\title{
¿ES DISCRIMINATORIA LA PREVISIÓN DE UN COMPLEMENTO DE DOCTORADO ÚNICAMENTE PARA DETERMINADAS FIGURAS DE PROFESORADO UNIVERSITARIO? COMENTARIO DE LA STS DE 20 DE SEPTIEMBRE DE 2018
}

\author{
Josep Moreno Gené ${ }^{1}$ \\ Profesor Titular Derecho del Trabajo y de la Seguridad Social \\ Universitat de Lleida
}

\begin{abstract}
La Sentencia del Tribunal Supremo de 20 de septiembre de 2018 objeto de este comentario analiza si la regulación del complemento por doctorado que se contiene en un convenio colectivo se ajusta o no a lo preceptuado por la Directiva 1999/70/CE y, en particular, si en el diseño del mismo se trata a los trabajadores con un contrato de duración determinada de una manera menos favorable que a los trabajadores fijos comparables por el mero hecho de tener un contrato de duración determinada, sin que se justifique este trato diferente por razones objetivas.
\end{abstract}

The sentence of the Supreme Court Judgment of 20 September 2018, which is the subject of this comment, analyses whether the regulation of the doctoral supplement contained in a collective agreement conforms with Directive 1999/70/EC and, in particular, whether the collective agreement offers a less favourable treatment to workers with a fixed-term contract than to comparable workers on an open-ended contract, with no objective justification for this differentiation.

Tittle: Is the forecasting of a doctoral complement only for certain university teachers discriminatory? Comment of the decision of the Spanish Supreme Court of September 20, 2018 .

Palabras clave: complemento salarial, profesorado universitario, principio de no discriminación, convenio colectivo, Directiva 1999/70/CE

Keywords: Wage supplement, university teaching staff, collective agreement, principle of non-discrimination, Directive 1999/70/EC

IUSLabor 2/2019, ISSN 1699-2938, p. 135-152

DOI 10.31009/IUSLabor.2019.i02.08

\footnotetext{
${ }^{1}$ El autor es miembro del grupo de investigación consolidado reconocido por la Generalitat de Cataluña "Social and Business Research Laboratory" (SBRLab). Ref. 2017 SGR 1572.
} 


\section{Sumario}

1. El supuesto litigioso: La previsión en convenio colectivo de un complemento de doctorado exclusivamente para determinadas figuras de profesorado universitario

2. La respuesta de instancia: STSJ de Andalucía (Sevilla) de 19 de octubre de 2016

3. La respuesta en casación: STS de 20 de septiembre de 2018

3.1. La inexistencia de trato desigual entre profesores universitarios indefinidos y temporales

3.2. La ausencia de una diferencia de trato injustificada entre profesores universitarios temporales

4. Valoración final

5. Bibliografía 


\section{El supuesto litigioso: la previsión en convenio colectivo de un complemento de doctorado exclusivamente para determinadas figuras de profesorado universitario}

Como es bien conocido, la aprobación de la Ley Orgánica 6/2001, de 21 de diciembre, de Universidades (en adelante, Ley Orgánica 6/2001) comportó una modificación radical del régimen jurídico del personal docente e investigador de las universidades públicas existente con anterioridad a su aprobación, siendo una de las principales novedades introducidas el carácter laboral de la contratación de una parte de este personal. En consecuencia, tras la entrada en vigor de la Ley Orgánica 6/2001 se implantó un modelo o sistema mixto, en el que coexisten dos regímenes jurídicos diversos en relación con el personal docente e investigador, con las consecuentes dificultades de gestión que ello supone: el funcionarial o estatutario, por el que se rigen los profesores integrados en los cuerpos docentes y el laboral aplicable sobre todos los profesores contratados.

Entre los profesores contratados, el vigente 48.1 de la Ley Orgánica 6/2001 establece que "las universidades podrán contratar personal docente e investigador en régimen laboral, a través de las modalidades de contratación laboral específicas del ámbito universitario que se regulan en esta Ley o mediante las modalidades previstas en el Estatuto de los Trabajadores para la sustitución de trabajadores con derecho a reserva del puesto de trabajo. También podrán contratar personal investigador, técnico u otro personal, a través del contrato de trabajo por obra o servicio determinado, para el desarrollo de proyectos de investigación científica o técnica. Asimismo, las universidades podrán nombrar profesoras y profesores eméritos en las condiciones previstas en esta Ley"2. Entre las modalidades específicas del ámbito universitario, el redactado vigente del artículo 48.2 de la Ley Orgánica 6/2001 incluye las figuras de ayudante, profesor ayudante doctor, profesor contratado doctor, profesor asociado y profesor visitante. Por el contrario, tras la Ley Orgánica 4/2007, de 12 de abril, por la que se modifica la Ley Orgánica 6/2001, de 21 de diciembre de 2001, de Universidades se ha procedido a suprimir la figura del profesor colaborador, si bien, se ha previsto que quienes a la entrada en vigor de la misma estuvieran contratados como tales podrán continuar en el desempeño de sus funciones docentes e investigadoras en los términos previstos por la ley.

\footnotetext{
${ }^{2}$ Un análisis exhaustivo de este precepto en MoReno GenÉ, J. y RoMERo BuRILLO, A. M., "La contratación laboral del personal docente e investigador en las universidades públicas", en SEMPERE NAVARRO, A.V. y CARDEnal CARRo, M. (Dirs.), El contrato de trabajo. Volumen II. Relaciones laborales especiales y contratos con particularidades, Aranzadi-Thomson Reuters, Cizur Menor (Navarra), 2011. Vid. también, BAYLOS GRAU, A., "El personal docente e investigador contratado en régimen laboral después de la reforma de la LOU en 2007", Revista de Derecho Social, núm. 44, 2008 y RivERA SÁnCHEZ, J.R., "Los contratos de trabajo del personal docente e investigador en la vigente Ley Orgánica de Universidades", en BALLESTER LAGUNA, F. (Coord.), El Estatuto profesional del personal investigador contratado en régimen laboral, INAP, Madrid, 2016.
} 
La Ley Orgánica 6/2001 no se limita a enumerar las distintas figuras de personal docente e investigador contratado, sino que, por el contrario, también contempla el régimen jurídico por el que deben regularse dichas figuras. A tal efecto, el citado artículo 48.2 de la Ley Orgánica 6/2001 indica que "el régimen de las indicadas modalidades de contratación laboral será el que se establece en esta Ley y en sus normas de desarrollo, supletoriamente, será de aplicación lo dispuesto en el Estatuto de los Trabajadores (...), y en sus normas de desarrollo". A lo que cabe añadir lo previsto en el artículo 48.6 de la Ley Orgánica 6/2001 en virtud del cual "en los términos de la presente ley y en el marco de sus competencias, las Comunidades Autónomas establecerán el régimen del personal docente e investigador contratado de las universidades"; previsión que posibilita la intervención de las Comunidades Autónomas en este ámbito, siempre claro está, dentro de sus competencias de ejecución de la legislación laboral previstas en el artículo 149.1.7 $\mathrm{CE}^{3}$.

Sorprendentemente, la Ley Orgánica 6/2001 no contiene ninguna alusión a la negociación colectiva como fuente reguladora del régimen jurídico del personal docente e investigador contratado de las universidades públicas; sin embargo, la alusión genérica que dicha norma efectúa al Estatuto de los Trabajadores y a sus normas de desarrollo dan pie a que las relaciones laborales de este colectivo también se rijan por lo previsto en la negociación colectiva y, específicamente, en los convenios colectivos que resulten de aplicación ${ }^{4}$.

En este punto, encuentra su origen la controversia que se aborda en la Sentencia del Tribunal Supremo de 20 de septiembre de 2018 objeto de este comentario ${ }^{5}$. A tal efecto, la citada resolución aborda la legalidad del Primer Convenio colectivo para el Personal Docente e Investigador Laboral de las Universidades Públicas de Andalucía, en la medida que mientras prevé un complemento mensual por doctorado para determinadas figuras de profesorado lo excluye para otras. En este punto, el Sindicato Andaluz de Trabajadores (en adelante, SAT) que interpone el conflicto colectivo contra el referido convenio colectivo considera que dicha previsión podría resultar contraria a la cláusula 4.1 de la Directiva 1999/70/CE del Consejo, de 28 de junio, relativa al Acuerdo marco de la CES, la UNICE y la CEEP sobre el trabajo de duración determinada (en adelante, Directiva 1999/70/CE).

\footnotetext{
${ }^{3}$ Sobre el papel de la normativa autonómica en esta materia vid. CAPODIFERRO CUBERO, D., "El régimen jurídico del profesorado contratado en el sistema universitario público", Revista Vasca de Administración Pública, nº 104-I, 2016, p. 19-57.

${ }^{4}$ Sobre la importancia de la negociación colectiva en la regulación de las condiciones laborales del personal docente e investigador contratado de las universidades públicas vid. MORENo GENÉ, J. y FeRnÁNDEZ VILLAZÓN, L. (Coords.), La negociación colectiva del personal docente e investigador laboral de las universidades públicas, Tirant lo Blanch, Valencia, 2010.

${ }^{5}$ JUR\2018\285171.
} 
Bajo estas premisas, en los próximos apartados analizaremos si la regulación del complemento por doctorado que se contiene en el Primer Convenio colectivo para el Personal Docente e Investigador Laboral de las Universidades Públicas de Andalucía se ajusta o no a lo preceptuado por la Directiva 1999/70/CE que establece la igualdad de trato entre trabajadores fijos y temporales, así como si el mismo constituye o no una diferencia de trato injustificada entre trabajadores temporales.

\section{La respuesta de instancia: STSJ de Andalucía (Sevilla) de 19 de octubre de 2016}

Por lo que respecta a la cuestión de si la regulación del complemento por doctorado que se contiene en el Primer Convenio colectivo para el Personal Docente e Investigador Laboral de las Universidades Públicas de Andalucía se ajusta o no a lo preceptuado por la Directiva 1999/70/CE, cabe traer a colación los diferentes preceptos del convenio colectivo que regulan el referido complemento por doctorado. En primer lugar, el artículo 45.1 prevé que "se establece para las categorías de profesor colaborador y de ayudante un complemento mensual por doctorado en la cuantía igual al 5\% de las retribuciones básicas de un profesor titular de universidad". En segundo lugar, el artículo 45.2 establece que "este complemento se abonará, previa solicitud y justificación documental, en dos escalones: a) Un 2\% tras la obtención del Diploma de Estudios Avanzados o la superación del período de formación de las enseñanzas de Doctorado previstas en el artículo 18 del Real Decreto 1393/2007 (...) b) y el 3\% restante tras la obtención del título de doctor". En tercer lugar, el artículo 45.3 indica que "las personas incluidas en el ámbito de este convenio que a 1 de enero de 2008 estén contratadas como ayudante de nivel II o como profesor colaborador de nivel II pasarán a percibir, de oficio, este complemento a partir del 1 de enero de 2008". En cuarto lugar, el artículo 42.4 d) dispone que "a partir del año 2010, los profesores asociados y los profesores asociados CIS tendrán derecho al complemento por doctorado en los términos establecidos en el artículo 45 de este convenio". Y, finalmente, el artículo 42.5 establece que "las retribuciones de los profesores sustitutos interinos será la establecida, en función de su dedicación docente, en la siguiente tabla, sin que les sea de aplicación el complemento por doctorado".

Como puede observarse, el Primer Convenio colectivo para el Personal Docente e Investigador Laboral de las Universidades Públicas de Andalucía prevé un complemento salarial que se reconoce a algunas figuras de profesorado y no a otras. A tal efecto, inicialmente únicamente se reconoce el referido complemento a las figuras de profesor colaborador y de ayudante, si bien, se prevé que, a partir del año 2010, el mismo se extienda también a los profesores asociados y a los profesores asociados CIS; excluyéndose del mismo, por el contrario, de forma expresa a los profesores sustitutos interinos. 
Es en este punto donde se plantea la cuestión de si esta previsión se ajusta o no a lo preceptuado por la Directiva 1999/70/CE y, en particular, a lo establecido en el artículo 4 de dicha norma que bajo el título de "principio de no discriminación" establece en su apartado 1 que "por lo que respecta a las condiciones de trabajo, no podrá tratarse a los trabajadores con un contrato de duración determinada de una manera menos favorable que a los trabajadores fijos comparables por el mero hecho de tener un contrato de duración determinada, a menos que se justifique un trato diferente por razones objetivas".

Como acertadamente pone de manifiesto la Sentencia del Tribunal Superior de Justicia de Andalucía (Sevilla) de 19 de octubre de $2016^{6}$, no cabe duda de que el complemento de doctorado previsto en el Primer Convenio colectivo para el Personal Docente e Investigador Laboral de las Universidades Públicas de Andalucía constituye una condición de trabajo, por estar incluido entre los derechos otorgados a los trabajadores en virtud de una relación de empleo con las universidades empleadoras. A tal efecto, la citada resolución judicial se apoya en el concepto de "condiciones de trabajo" elaborado por la doctrina del Tribunal de Justicia de la Unión Europea, según el cual "el criterio decisivo para determinar si una medida está incluida en este concepto es precisamente el del empleo, es decir, la relación laboral entre un trabajador y un empresario" 7 .

Tratándose el complemento de doctorado de una condición laboral, debe analizarse si en el diseño del mismo que se contiene en el Primer Convenio colectivo para el Personal Docente e Investigador Laboral de las Universidades Públicas de Andalucía se trata a los trabajadores con un contrato de duración determinada de una manera menos favorable que a los trabajadores fijos comparables por el mero hecho de tener un contrato de duración determinada, sin que se justifique este trato diferente por razones objetivas.

En este punto, la Sentencia del Tribunal Superior de Justicia de Andalucía (Sevilla) de 19 de octubre de 2016 recuerda el triple análisis que debe efectuarse para determinar cuando estamos o no ante una auténtica diferencia de trato no justificada, a saber: a) La existencia de una situación comparable, lo que requiere que el término de comparación sea válido, por tratarse de situaciones homogéneas o equiparables; b) La existencia de una justificación objetiva y razonable para el trato desigual, que debe apreciarse en relación con la finalidad de la medida examinada; y, finalmente, c) Que exista una razonable proporcionalidad entre los medios empleados y la finalidad perseguida.

\footnotetext{
${ }^{6}$ AS\2016\1660.

${ }^{7}$ Vid. entre otras, Sentencias del Tribunal de Justicia de la Unión Europea de 12 de diciembre de 2013 (TJCE 2013, 448), asunto C-361/12; de 13 de marzo de 2014 (TJCE 2014, 101), asunto C-38/13 y de 14 de septiembre de 2016 (TJCE 2016, 111), asunto C-596/14.
} 
Pues bien, tras efectuar este triple análisis al supuesto enjuiciado, la Sentencia del Tribunal Superior de Justicia de Andalucía (Sevilla) de 19 de octubre de 2016 concluye que la cláusula 4 de Directiva 1999/70/CE no resulta de aplicación al mismo, pues las situaciones invocadas no son homogéneas, y por ello no son comparables y, además, la diferente retribución que en algunos casos se establece en el convenio está objetiva y razonablemente justificada.

La resolución judicial constata, en primer lugar, que lo que realmente establece la normativa convencional denunciada no constituye una diferencia de trato entre trabajadores con contrato indefinido respecto de trabajadores con contrato temporal, no en vano, no todas las figuras de profesorado a las que se reconoce el complemento de doctorado tienen la consideraron de trabajadores indefinidos, ni se niega el percibo de este complemento a todas las figuras de profesorado con contrato temporal. A tal efecto, la figura del profesor ayudante a la que se reconoce el derecho a percibir el complemento de doctorado se configura como una modalidad de contratación de carácter temporal y la figura del profesor colaborador que también puede acceder al referido complemento inicialmente podía tratarse tanto de un contrato temporal como de un contrato indefinido. Igualmente, los profesores asociados y asociados CIS, que siempre tienen vinculación temporal, también tienen derecho a percibir el referido complemento a partir del año 2010. Por otra parte, existen figuras de profesores con contrato temporal como los ayudantes doctores que no pueden acceder al complemento de doctor, al igual que tampoco pueden acceder al mismo, profesores con vinculación por tiempo indefinido como es el caso de los profesores contratados doctores. En definitiva, el criterio para el reconocimiento del complemento de doctorado no es el de unir a dicha titulación el carácter indefinido de su relación laboral con la correspondiente universidad, como lo prueba el hecho de que una parte de los profesores que sí lo tienen reconocido sean trabajadores con contrato temporal.

Pero, además, en segundo lugar, el Tribunal considera que la exclusión de determinados profesores del acceso al complemento, en particular, de los sustitutos interinos, no se fundamenta en el carácter temporal de su vínculo laboral, sino en la especial estructura retributiva que articula el convenio colectivo en su Título III atendiendo a la formación, funciones y finalidad de contratación de cada una de las categorías de personal docente e investigador. A tal efecto, la resolución objeto de este comentario estima que el otorgamiento del complemento por doctorado a los ayudantes y colaboradores encuentra su justificación objetiva y razonable en incentivar en éstos la feliz culminación de su formación académica e investigadora con la obtención del título de doctor. Por el contrario, estas finalidades son ajenas, en principio, al personal sustituto interino cuya contratación se justifica en la necesidad de cubrir transitoriamente necesidades puntuales y no con la finalidad de completar su formación. 


\section{La respuesta en casación: STS de 20 de septiembre de 2018}

3.1. La inexistencia de trato desigual entre profesores universitarios indefinidos y temporales

Ante la respuesta dispensada en instancia por el TSJ de Andalucía al conflicto colectivo planteado por el Sindicato Andaluz de Trabajadores, dicho sindicato interpone el correspondiente recurso de casación, por considerar que dicha resolución es contraria al derecho a la igualdad de trato entre trabajadores temporales e indefinidos, porque no habría ninguna razón objetiva que pudiera justificar el diferente tratamiento aplicado a uno y otro colectivo en lo que se refiere al devengo de dicho complemento retributivo. En otros términos, se mantiene en el recurso que las universidades demandadas han incurrido en un trato discriminatorio al aplicar una diferencia retributiva entre dos grupos de trabajadores en razón de la naturaleza temporal o indefinida de sus contratos de trabajo, al no abonar el complemento de doctorado previsto en el artículo 45 del Convenio Colectivo a quienes son contratados como profesores sustitutos interinos, sin que concurra ninguna razón objetiva que permita excluir a este colectivo del derecho a la percepción del complemento. Para ello, el recurso se apoya, fundamentalmente, en la doctrina de la Sentencia del Tribunal de Justicia de la Unión Europea (en adelante, STJUE) de 14 de diciembre de 2016 (asunto Diego Porras).

A tal efecto, cabe recordar que la referida STJUE de 14 de septiembre de 2016 (asunto Diego Porras) declara que "[1] a cláusula 4, apartado 1, del Acuerdo marco sobre el trabajo de duración determinada, celebrado el 18 de marzo de 1999, que figura en el anexo de la Directiva 1999/70/CE del Consejo, de 28 de junio de 1999, relativa al Acuerdo marco de la CES, la UNICE y la CEEP sobre el trabajo de duración determinada, debe interpretarse en el sentido de que el concepto de "condiciones de trabajo" incluye la indemnización que un empresario está obligado a abonar a un trabajador por razón de la finalización de su contrato de trabajo de duración determinada. La cláusula 4 del Acuerdo marco sobre el trabajo de duración determinada, que figura en el anexo de la Directiva 1999/70, debe interpretarse en el sentido de que se opone a una normativa nacional, como la controvertida en el litigio principal, que deniega cualquier indemnización por finalización de contrato al trabajador con contrato de interinidad, mientras que permite la concesión de tal indemnización, en particular, a los trabajadores fijos comparables. El mero hecho de que este trabajador haya prestado sus servicios en virtud de un contrato de interinidad no puede constituir una razón objetiva que permite justificar la negativa a que dicho trabajador tenga derecho a la mencionada indemnización". 
Frente a la invocación de la doctrina Diego Porras por la parte recurrente, el Tribunal Supremo, con una voluntad más bien pedagógica, como se pondrá de manifiesto más adelante, quiere dejar constancia de que esta doctrina ha venido a ser corregida por la STJUE de 5 de junio de 2018 (asunto Montero Mateos) ${ }^{8}$, procediendo a exponer a continuación el contenido de esta nueva doctrina del TJUE en los siguientes términos:

a) La Directiva tiene por objeto la aplicación del principio de igualdad a los trabajadores con contrato de duración determinada, "con la finalidad de impedir que una relación laboral de esta naturaleza sea utilizada por un empleador para privar a dichos trabajadores de derechos reconocidos a los trabajadores con contrato de duración determinada".

b) La finalidad anterior "incluye una prohibición de tratar, por lo que respecta a las condiciones de trabajo, a los trabajadores con un contrato de duración determinada de modo menos favorable que a los trabajadores fijos comparables por el mero hecho de tener un contrato de trabajo de duración determinada, a menos que se justifique un trato diferente por razones objetivas".

c) El principio de no discriminación, del que la cláusula 4, apartado 1, de la Directiva 1999/70/CE es una expresión concreta, exige que no se traten de manera diferente situaciones comparables y que no se traten de manera idéntica situaciones diferentes, a no ser que dicho trato esté objetivamente justificado.

d) A la hora de determinar si estamos ante situaciones iguales a estos efectos, debe tenerse en cuenta que "para apreciar si las personas de que se trata ejercen un trabajo idéntico o similar, en el sentido de la Directiva, debe comprobarse si, en virtud de las cláusulas 3, apartado 2, y 4 apartado 1, de dicha norma, habida cuenta de un conjunto de factores, como la naturaleza del trabajo, los requisitos de formación y las condiciones laborales, puede considerarse que estas personas se encuentran en una situación comparable".

e) El concepto de "razones objetivas" no permite justificar una diferencia de trato entre trabajadores con contrato de duración determinada y trabajadores fijos por el hecho

\footnotetext{
${ }^{8}$ Una valoración de esta resolución en Beltran de Heredia Ruiz, I., "Contratos temporales e indemnización por cumplimiento del término "de Diego Porras" vs. "Montero Mateos", Revista Información Laboral, $\mathrm{n}^{\circ}$ 7, 2018; MOLINA NAVARRETE, C., "La indemnización extintiva de los interinos (y demás temporales): ¿Fin de la historia o nuevo capítulo sin fin?”, Revista de Trabajo y Seguridad Social. $C E F, \mathrm{n}^{\circ}$ 424, 2018; PÉREZ ReY, J., “¿Punto y final a la doctrina Porras?: consideraciones acerca del giro jurisprudencial protagonizado por el TJUE en los casos Montero Mateos y Grupo Norte Facility", Trabajo y Derecho, $\mathrm{n}^{\circ}$ 46, 2018.
} 
de que aquella esté prevista por una norma general o abstracta, como una ley o un convenio colectivo, por el contrario, "este concepto requiere que la desigualdad de trato observada esté justificada por la existencia de elementos precisos y concretos, que caracterizan la condición de trabajo de que se trata, en el contexto específico en que se enmarca y con arreglo a criterios objetivos y transparentes, a fin de verificar si dicha desigualdad responde a una necesidad auténtica, si permite alcanzar el objetivo perseguido y si resulta indispensable al efecto". En este punto, "tales elementos pueden tener su origen, en particular, en la especial naturaleza de las tareas para cuya realización se celebran los contratos de duración determinada y en las características inherentes a las mismas o, eventualmente, en la persecución de un objetivo legítimo de politica social por parte de un Estado miembro".

A partir de estas premisas, la STS de 20 de septiembre de 2018 recuerda que la STJUE de 5 de junio de 2018 (asunto Montero Mateos) concluye, en relación con el supuesto enjuiciado por la misma, que "no se opone a la Directiva, la norma nacional que no contempla el abono de indemnización alguna a los trabajadores con contratos de duración determinada al momento de su extinción, mientras que se concede indemnización a los trabajadores fijos con motivo de la extinción de su contrato de trabajo por una causa objetiva".

Por todo ello, el Tribunal Supremo considera que la doctrina contenida en la STJUE de 5 de junio de 2018 (asunto Montero Mateos) corrige la doctrina anteriormente fijada por la STJUE de 14 de septiembre de 2016, en el sentido que no toda diferencia de trato entre trabajadores fijos y temporales resulta contraria a las previsiones de la Directiva 1999/70/CE, si concurren razones objetivas que justifican este diferente tratamiento. Señalando, además, el Alto Tribunal que este cambio de doctrina del TJUE se reitera en su posterior sentencia de 25 de julio de 2018 (asunto Vernaza Ayovi), cuando se invocan los mismos argumentos expuestos para negar al trabajador temporal el derecho de readmisión que reconoce a los trabajadores fijos en los casos de despido disciplinario declarado improcedente.

A mayor abundamiento, el Tribunal Supremo indica que esta doctrina resulta plenamente coincidente con la que vienen aplicando el Tribunal Constitucional y el Tribunal Supremo en materia de igualdad de trato de los trabajadores, conforme a los artículos 14 CE y 17.1 ET. A tal efecto, el Alto Tribunal trae a colación su sentencia de 14 de junio de 2018, de la que señala los siguientes extremos:

a) No toda desigualdad de trato supone infracción del artículo 14 CE sino, únicamente, aquella que carece de una justificación objetiva y razonable. 
b) El principio de igualdad exige que a iguales supuestos de hecho se apliquen iguales consecuencias jurídicas sin que sea factible ni correcto la introducción de elementos diferenciadores que sea arbitraria o carezca de fundamento racional.

c) El principio de igualdad no prohíbe cualquier desigualdad sino solo aquellas que resulten artificiosas o injustificadas por no venir fundadas en criterios objetivos, suficientemente, razonables.

d) Para que la diferenciación resulte constitucionalmente lícita no basta con que lo sea el fin que, con la misma, se persigue, sino que, además, resulta indispensable que las consecuencias jurídicas de tal diferenciación sean adecuadas y superen un juicio de proporcionalidad en sede constitucional.

Una vez expuesta la nueva doctrina europea y nacional sobre la materia, el Tribunal Supremo procede a aplicar esta doctrina al supuesto enjuiciado, para lo cual, primero debe procederse a constatar si los trabajadores fijos y temporales se encuentran en situaciones jurídicas comparables a los efectos de la condición de trabajo de que en cada caso se trate $\mathrm{y}$, en caso afirmativo, determinar si concurren razones objetivas que pudieran justificar el desigual tratamiento aplicado a unos y a otros.

Pues bien, en este punto, el Tribunal mantiene que en el supuesto enjuiciado falta la premisa inicial al considerar que no puede sostenerse que nos encontramos ante una situación jurídica que afecte a la igualdad de trato entre trabajadores fijos y temporales, no en vano, la cláusula controvertida del Convenio Colectivo prevé entre quienes pueden percibir este complemento a los profesores ayudantes, que por definición son trabajadores temporales, "lo que impide que concurra el presupuesto básico que pudiere valer de punto de partida".

A tal efecto, con cita de la sentencia de instancia se considera que "si los trabajadores bajo esta modalidad de contratación temporal de profesores ayudantes son los que perciben el complemento por doctorado cuando reúnen los requisitos convencionalmente exigidos, de ninguna manera podrá sostenerse que la exclusión de los profesores sustitutos interinos suponga una desigualdad de trato respecto a los trabajadores con contrato indefinido".

A criterio del Tribunal Supremo, no se opone a esta conclusión el hecho de que se reconozca el derecho a percibir este complemento de doctorado a otros colectivos de profesores, preferentemente contratados por tiempo indefinido, puesto que ello deriva del régimen transitorio generado tras el cambio del marco normativo regulador del profesorado operado en su momento por la Ley Orgánica 4/2007. 
En definitiva, el Alto Tribunal rechaza cualquier vulneración de la igualdad de trato entre trabajadores fijos y temporales, proscrita tanto en la normativa comunitaria como en la estatal, al considerar que "la percepción del complemento resulta absolutamente ajena a la duración indefinida del contrato de trabajo, no se sustenta en esta previa condición ni tiene por razón de ser el carácter fijo de la relación laboral".

Por esta razón, indicábamos que la extensa exposición que lleva a cabo el Tribunal Supremo sobre el cambio de criterio de la doctrina del TJUE en esta materia tenía un carácter meramente pedagógico, no en vano, faltando la premisa inicial de que no puede sostenerse que nos encontramos ante una situación jurídica que afecte a la igualdad de trato entre trabajadores fijos y temporales, no resultaba aplicable al supuesto enjuiciado en ningún caso la doctrina establecida por el tribunal europeo, ni la establecida en su momento en la STJUE de 14 de septiembre de 2016 (asunto Diego Porras), ni en la STJUE de 5 de junio de 2018 (asunto Montero Mateos).

\subsection{La ausencia de una diferencia de trato injustificada entre profesores universitarios temporales}

Descartada la posibilidad de que en el supuesto enjuiciado nos encontremos ante una situación jurídica que afecte a la igualdad de trato entre trabajadores fijos y temporales, el Tribunal Supremo aborda la posibilidad de que nos encontremos ante una diferencia de trato injustificada entre trabajadores temporales, posibilidad también proscrita por nuestro ordenamiento jurídico.

Pues bien, tampoco recibe una acogida favorable esta segunda posibilidad por parte el Tribunal Supremo, al considerar que no nos encontramos ante un complemento de calidad que estuviese previsto en favor de todos los trabajadores que ostenten el título de doctorado, lo cual podría justificar su devengo por quienes sean contratados como interinos y ostenten esa misma titulación, sino que, el Alto Tribunal mantiene que la finalidad del citado complemento es la de fomentar e incentivar el proceso formativo de los profesores ayudantes para estimular la consecución del doctorado, que viene a configurarse como la meta a la que precisamente está dirigida este tipo de contratación y que viene a ser un elemento circunstancial a su propia existencia, teniendo en cuenta que, como indica el artículo 49 LOU, "la finalidad principal del contrato será la de completar la formación docente e investigadora de dichas personas".

El Tribunal Supremo refuerza es apreciación con la constatación de que el derecho a percibir el complemento se encuentra directa y exclusivamente vinculada al proceso formativo para el que precisamente está prevista la figura del profesor ayudante, y es inherente a la propia naturaleza jurídica de esta clase de contrato temporal. Ello se deduce 
de la propia configuración del complemento de doctorado que se fija en cuantía del 5\% de las retribuciones básicas de un profesor titular y contempla dos escalones diferentes para su devengo: un 2\% tras la obtención del Diploma de Estudios Avanzados o la superación del período de formación de doctorado, y el 3\% restante tras la obtención del título de doctor.

En definitiva, el hecho de que el complemento de doctorado tenga la función de fomentar e incentivar el proceso formativo de los profesores ayudantes, lleva al Tribunal Supremo a concluir que resulta perfectamente justificado que se excluya de su percepción a los profesores sustitutos interinos, porque su contratación no tiene como finalidad la de completar su formación docente, sino la de sustituir las vacantes que temporalmente pudieren existir en la plantilla de profesorado. Esta circunstancia constituye, precisamente, la razón objetiva que justifica la exclusión de este colectivo del acceso al citado complemento de doctorado.

\section{Valoración final}

El complemento de doctorado se configura como un complemento salarial recogido en diferentes convenios colectivos del personal docente e investigador contratado por las universidades públicas, que tiene por finalidad retribuir un determinado nivel de formación del personal docente e investigador, concretamente el referido a la obtención del doctorado 9 . Se trata en última instancia de un complemento salarial que responde a las características definidoras de un complemento ligado a las condiciones personales del trabajador (artículo 26.2 del Real Decreto Legislativo 2/2015, de 23 de octubre, por el que se aprueba el Texto Refundido de la Ley del Estatuto de los Trabajadores), al tratarse de una partida salarial que compensa económicamente una determinada cualificación profesional del trabajador que sin ser requisito indispensable para el correcto desarrollo de las tareas que el mismo tiene encomendadas repercute positivamente en el trabajo realizado ${ }^{10}$.

\footnotetext{
${ }^{9}$ A título de ejemplo, además del Primer Convenio colectivo para el Personal Docente e Investigador Laboral de las Universidades Públicas de Andalucía objeto de análisis en este comentario, se encuentran complementos similares en el art. 36.2 del Convenio colectivo del personal laboral docente e investigador de la UPV/EHV (Boletín Oficial del País Vasco de 22 de julio de 2005) y en el art. 35.4 del II Convenio colectivo para el personal laboral docente e investigador de la Universidad de Castilla-La Mancha (Diario Oficial de Castilla y la Mancha de 1 de noviembre de 2006). Vid. MORENO GENÉ, J., "Balance de diez años de negociación colectiva del PDI laboral de las universidades públicas", en XI y XII Seminarios sobre aspectos jurídicos de la gestión universitaria, Thomson Reuters Aranzadi, Cizur Menor (Navarra), 2018, p. 1773.

${ }^{10}$ Vid. Romero Burillo, A. M., "Régimen retributivo", en Moreno Gené, J. y Fernández Villazón, L. (Coords.), La negociación colectiva del personal docente e investigador laboral de las universidades públicas, Tirant lo Blanch, Valencia, 2010, p. 444. La autora pone de manifiesto que se trata de un
} 
Esta configuración del complemento de doctorado explica porque el mismo no se percibe por aquellas figuras de profesorado que contemplan como uno de sus requisitos de acceso precisamente el estar en disposición del título de doctor, como es el caso, de los profesores ayudantes doctores y de los profesores contratados doctores, mientras que sí se prevé para aquellas figuras entre cuyos requisitos de acceso no se incluye estar en posesión del título de doctor, como es el caso paradigmático de los ayudantes y de los profesores colaboradores.

En consecuencia, la previsión de un complemento de estas características a priori no sólo resulta admisible jurídicamente, sino incluso aconsejable desde la óptica de una adecuada gestión de los recursos humanos, en aras a fomentar la mejora de la formación y/o cualificación profesional del profesorado contratado de las universidades públicas, lo que en última instancia debe repercutir en un mejor desarrollo de las carreras profesionales de los profesores universitarios y de las funciones docentes e investigadoras que los mismos tienen encomendadas.

Los problemas surgen cuando este complemento de doctorado únicamente se reconoce a determinadas figuras de profesorado, al tiempo que se excluye del mismo a otras. Cuando este $u$ otros tratamientos desiguales se producen entre profesores con contrato indefinido y profesores con contrato temporal, puede acudirse a la Directiva 1999/70/CE y la doctrina judicial interpretativa de la misma, que proscriben el trato desigual entre trabajadores temporales e indefinidos. Este fue, precisamente, el recurso al que se acudió en su momento para equiparar las indemnizaciones que corresponde percibir por finalización del contrato de trabajo a ambos colectivos de profesores universitarios. A tal efecto, la STSJ de Castilla y León (Valladolid) de 18 de septiembre de 2017 procedió a aplicar la doctrina contenida en la STJUE de 14 de septiembre de 2016 al supuesto enjuiciado $\mathrm{y}$, en consecuencia, al considerar que no concurría causa objetiva que justificara el trato desigual a los efectos indemnizatorios en la extinción del contrato de la profesora ayudante doctora respecto de un trabajador fijo comparable de la misma universidad, procedió a reconocer su derecho a percibir la indemnización prevista en el artículo 53 ET, por importe de veinte días de salario por año de servicio realizado. En parecidos términos, la STSJ de Castilla y León (Valladolid) de 1 de marzo de 2018 identifica a la figura del profesor contratado doctor como "un trabajador fijo comparable" a la figura del ayudante y, a partir de esta premisa, al no concurrir causa objetiva que justifique el trato desigual a los efectos indemnizatorios en la extinción del contrato de ayudante respecto de un trabajador fijo comparable de la misma universidad, reconoce su

complemento salarial que se reconoce en exclusiva a un conjunto de figuras de profesorado que de acuerdo con lo previsto en la Ley Orgánica 6/2001 no requiere para su contratación la acreditación de estudios de doctorado. Vid. también, Romero Burillo, A. M., El régimen retributivo del personal docente e investigador laboral de las Universidades Públicas, Atelier, Barcelona, 2011, p. 58 y 59. 
derecho a percibir la indemnización prevista en el artículo 53 ET, por importe de veinte días de salario por año de servicio realizado. Sin embargo, como ya se ha encargado de recordar el Tribunal Supremo en la sentencia objeto de este comentario, cabe poner de manifiesto el cambio de doctrina en esta materia efectuada por el TJUE en sendas sentencias de 5 de junio de 2018 (asuntos Montero Mateos y Grupo Norte Facility), lo que probablemente va a hacer imposible a partir de este momento que los profesores universitarios con vinculación temporal puedan acceder a indemnización alguna a la finalización de su contrato. Ello no impide, sin embargo, que el recurso a la Directiva 1999/70/CE siga siendo el instrumento idóneo para luchar contra cualquier tratamiento desigual entre trabajadores temporales e indefinidos y, por extensión, entre profesores universitarios con vínculo temporal o indefinido.

Si bien, cuando el trato desigual se produce entre diferentes categorías de profesores universitarios, con independencia de su vinculación indefinida o temporal, ya no puede acudirse a la Directiva 1999/70/CE, aún cabe la posibilidad de analizar si se trata de una diferencia de trato injustificada, posibilidad también proscrita por nuestro ordenamiento jurídico. Este es el supuesto que se contempla, por ejemplo, en la Sentencia del Juzgado de lo Social núm. 26 de Barcelona en la que se considera injustificado el trato que recibían los profesores asociados a tiempo parcial a la hora de computar su actividad docente, respecto al dispensado a otros colectivos de profesorado universitario. A tal efecto, dicha sentencia, con apoyo de la STJUE de 13 de marzo de 2014 y la doctrina general recogida en la STS de 2 de febrero de 2018, sobre qué debe entenderse por vulneración del principio de igualdad y no discriminación, que a su vez se remite a la doctrina del Tribunal Constitucional al respecto, considera que la decisión adoptada por el Consejo de Gobierno de la Universidad de Barcelona no es conforme a derecho e introduce un factor de discriminación (en términos directos de carga docente como indirecto de valoración económica de cada hora de trabajo) que carece de justificación objetiva y razonable, por lo que debe ser considerado discriminatorio.

Ninguno de los supuestos planteados, sin embargo, ha tenido lugar en el supuesto enjuiciado por la STS de 20 de septiembre de 2018, en la que se ha considerado que no nos encontramos ni ante un trato desigual entre trabajadores indefinidos y temporales, ni ante una diferencia de trato injustificada entre trabajadores temporales. En el primer caso, por haberse considerado que no se cumple la premisa necesaria para que nos encontramos ante una situación jurídica que afecte a la igualdad de trato entre trabajadores fijos y temporales, no en vano, el complemento de doctorado se reconoce indistintamente a profesores de ambas categorías. En el segundo caso, por considerarse que existe una razón objetiva -fomento del proceso formativo de los profesores ayudantes- que justifica la diferencia de trato entre las diferentes categorías de profesorado. 
Ahora bien, con independencia de que, como sucede en el supuesto enjuiciado, el criterio adoptado pueda ajustarse a la legalidad por tener una justificación objetiva y razonable, en concreto, incentivar la culminación de la formación académica e investigadora de determinadas figuras de profesorado con la obtención del título de doctor, la opción de contemplar el complemento de doctorado exclusivamente respecto a determinadas figuras de profesorado universitario encierra cuanto menos dos peligros.

Un primer peligro consiste en que a la hora de diseñar el complemento de doctorado se acostumbra a atender exclusivamente a la delimitación legal de cada figura de profesorado, sin tener en cuenta los perfiles reales de quienes son contratados mediante las mismas. A tal efecto, sin bien, formalmente, puede calificarse como un criterio objetivo y razonable no asignar estos complementos a los profesores asociados y a los profesores sustitutos, por considerar que en los mismos no concurre la finalidad de incentivar la formación académica e investigadora, sino que, por el contrario, los primeros son contratados para aportar su experiencia profesional a la universidad y los segundos para cubrir de forma transitoria necesidades puntuales de docencia, en la práctica y como consecuencia de los recortes presupuestarios estas figuras contractuales son ocupadas en no pocas ocasiones por profesores que no han podido acceder a figuras contractuales adecuadas pero que también se encuentran en una fase de formación y, por tanto, también deberían poder acceder al complemento de doctorado.

El segundo peligro que entraña la previsión del complemento de doctorado en relación con diferentes figuras de profesorado consiste en que puede contribuir a enmascarar la situación de precariedad en la que se encuentran muchos profesores universitarios doctores que, también por motivos presupuestarios, ocupan una figura de profesorado para la que no se requiere la titulación de doctor. En estos supuestos, aunque la finalidad sea loable, el papel de la negociación colectiva no puede consistir en paliar el agravio económico que se deriva de esta situación, mediante la previsión de un complemento económico, sino que deben establecerse los mecanismos necesarios para favorecer la promoción profesional de los profesores afectados a las figuras de profesorado que les corresponden por su nivel de titulación y acreditaciones obtenidas ${ }^{11}$.

\footnotetext{
${ }^{11}$ Sobre las posibilidades de la negociación colectiva en este punto vid. MoReno GenÉ, J., "Carrrera académica, promoción profesional y estabilidad en el empleo", en MORENo GENÉ, J. y VILLAZÓN FERNÁNDEZ, L. (Coords.), La negociación colectiva del personal docente e investigador laboral de las universidades públicas, Tirant lo Blanch, Valencia, 2010, p. 247 y ss. Vid. también MORENO GENÉ, J., "La carrera profesional del personal docente e investigador laboral de las universidades públicas: figuras contractuales y mecanismos de promoción y estabilización", Revista de Trabajo y Seguridad Social. CEF, $\mathrm{n}^{\circ} 37,2009$.
} 


\section{Bibliografía}

Baylos Grau, A., "El personal docente e investigador contratado en régimen laboral después de la reforma de la LOU en 2007”, Revista de Derecho Social, n 44, 2008.

BELTRAN DE HEREDiA RuIZ, I., "Contratos temporales e indemnización por cumplimiento del término "de Diego Porras" vs. "Montero Mateos", Revista Información Laboral, $\mathrm{n}^{\circ} 7$, 2018 .

CAPOdifERro Cubero, D., "El régimen jurídico del profesorado contratado en el sistema universitario público", Revista Vasca de Administración Pública, no 104-I, 2016.

Molina Navarrete, C., "La indemnización extintiva de los interinos (y demás temporales): ¿Fin de la historia o nuevo capítulo sin fin?”, Revista de Trabajo y Seguridad Social. CEF, no 424, 2018.

MoREnO GENÉ, J., "La carrera profesional del personal docente e investigador laboral de las universidades públicas: figuras contractuales y mecanismos de promoción y estabilización", Revista de Trabajo y Seguridad Social. CEF, n 37, 2009.

MoReno GenÉ, J., "Carrrera académica, promoción profesional y estabilidad en el empleo”, en Moreno Gené, J. y Villazón Fernández, L. (Coords.), La negociación colectiva del personal docente e investigador laboral de las universidades públicas, Tirant lo Blanch, Valencia, 2010.

Moreno GenÉ, J., "Balance de diez años de negociación colectiva del PDI laboral de las universidades públicas", en XI y XII Seminarios sobre aspectos jurídicos de la gestión universitaria, Thomson Reuters Aranzadi, Cizur Menor (Navarra), 2018.

Moreno Gené, J. y Fernández ViLlazón, L. (Coords.), La negociación colectiva del personal docente e investigador laboral de las universidades públicas, Tirant lo Blanch, Valencia, 2010.

Moreno Gené, J. y Romero Burillo, A. M., "La contratación laboral del personal docente e investigador en las universidades públicas", en SEMPERE NAVARro, A.V. y CARDEnAl CARro, M. (Dirs.), El contrato de trabajo. Volumen II. Relaciones laborales especiales y contratos con particularidades, Aranzadi-Thomson Reuters, Cizur Menor (Navarra), 2011. 
PÉREZ REY, J., “¿Punto y final a la doctrina Porras?: consideraciones acerca del giro jurisprudencial protagonizado por el TJUE en los casos Montero Mateos y Grupo Norte Facility", Trabajo y Derecho, $\mathrm{n}^{\circ}$ 46, 2018.

RIVERA SÁNCHEZ, J. R., "Los contratos de trabajo del personal docente e investigador en la vigente Ley Orgánica de Universidades", en BALLESTER LAGUNA, F. (Coord.), El Estatuto profesional del personal investigador contratado en régimen laboral, INAP, Madrid, 2016.

Romero Burillo, A. M., "Régimen retributivo", en Moreno Gené, J. y Fernández VILlAzón, L. (Coords.), La negociación colectiva del personal docente e investigador laboral de las universidades públicas, Tirant lo Blanch, Valencia, 2010.

ROMERo BuriLlo, A. M., El régimen retributivo del personal docente e investigador laboral de las Universidades Públicas, Atelier, Barcelona, 2011. 